\title{
Genetic Predisposition to 4NQO-Induced Tongue Carcinogenesis in the Rat
}

\author{
Jun-ichi Tanuma ${ }^{a}$ Masato Hirano ${ }^{a}$ Yoshikazu Hirayama ${ }^{a}$ Ichiro Semba $^{a}$ \\ Kotaro Ogawa ${ }^{a}$ Hayase Shisa $^{b}$ Hiroshi Hiaic $^{c}$ Motoo Kitano $^{d}$ \\ ${ }^{a}$ Department of Oral Pathology, Field of Oncology, Kagoshima University Graduate School of Medical and \\ Dental Sciences, Kagoshima, b Laboratory of Basic Cancer Study, Saitama Cancer Center Research Institute, Ina, \\ Saitama, ${ }^{\mathrm{c} S h i g a}$ Medical Center, Moriyama, Shiga, and ${ }^{\mathrm{d}}$ Department of Medical Research and \\ Clinical Pathology, Nakatsu Municipal Hospital, Nakatsu, Japan
}

\section{Key Words}

4-Nitroquinoline 1-oxide - Tongue cancer - Rat ·

Genetic susceptibility - Quantitative trait loci $\cdot$ Loss of heterozygosity

\begin{abstract}
Objective: This study aims to elucidate the genetic basis of predisposition to 4-nitroquinoline 1-oxide (4NOO)-induced tongue cancers (TCs). Materials and Methods: We have reported that inbred Dark-Agouti (DA) strain rats were highly susceptible to 4NOO-induced TCs, whereas Wistar/Furth (WF) rats were resistant to tongue squamous cell carcinomas induced by oral administration of $4 \mathrm{NOO}$. Using size and number of the tumours as quantitative parameters, responsible host loci were analysed by an interval mapping of $F_{2}$ intercross of DA and WF given carcinogenic regimen. Also, loss of heterozygosity ( $\mathrm{LOH})$ at these loci was analysed in tongue cancers in $(D A \times W F) F_{1}$. Results: We identified and mapped 5 significant quantitative trait loci (OTL), the Tongue squamous cell carcinoma 1-5 (Tscc1-5), and several other suggestive OTL that determine susceptibility to 4NOOinduced TC. Study of TCs induced in (DA $\times W F) F_{1}$ rats revealed a high frequency of LOH in the chromosomal regions of $T s c c 2,3$, and 4 and also of suggestive QTL on chromosomes 5 and 6 . The fact that $\mathrm{LOH}$ was found only
\end{abstract}

in larger TCs indicates that $\mathrm{LOH}$ occurred in the process of tumour progression. In most $\mathrm{LOH}$, the allele of the resistant WF strain was lost, suggesting that these loci may encode tumour suppressor genes. In larger TCs, in addition to $\mathrm{LOH}$, point mutations and the methylation of possible candidate genes were accumulated. Conclusion: These observations indicate that the $4 \mathrm{NOO}$-induced TC in the rat is a multifactorial disease of a polygenic trait. This model will be useful to understand the complicated genetic basis of predisposition to oral cancers.

Copyright $\odot 2005$ S. Karger AG, Basel

\section{Introduction}

Oral cavity cancers, including tongue cancer (TC), are ranked sixth as a cause of death due to malignancy, and their incidence is increasing [1-5]. It is important to identify the genetically predisposed group that is at risk for oral cavity cancers, and to determine molecular targets for effective treatment. We have established a rat model to dissect the genetic predisposition to TCs induced by a chemical carcinogen, 4-nitroquinoline 1-oxide (4NQO). The model is based on our observation that Dark-Agouti (DA) rats are extremely susceptible to TC by oral administration of 4NQO, while Wistar/Furth (WF) rats are resistant [6-9].

\section{KARGER}

Fax +4161306 1234 E-Mail karger@karger.ch www.karger.com
(C) 2005 S. Karger AG, Basel

$1011-7571 / 05 / 0145-0297 \$ 22.00 / 0$

Accessible online at:

www.karger.com/mpp
Dr. Jun-ichi Tanuma

Department of Oral Pathology, Field of Oncology

Kagoshima University Graduate School of Medical and Dental Sciences

Kagoshima 890-8544 (Japan)

Tel. +81992756142, Fax +81992756148, E-Mail tanuma@dentb.hal.kagoshima-u.ac.jp 
To elucidate the genetic predisposition to TC, $(\mathrm{DA} \times$ WF) $\mathrm{F}_{2}$ rats were given 4NQO, and interval mapping of the genetic loci affecting the TC phenotype was carried out to find multiple quantitative trait loci (QTL). To test whether an individual locus has an allele-specific tumour suppressor-like activity against TC, 4NQO-induced TCs in $(\mathrm{DA} \times \mathrm{WF}) \mathrm{F}_{1}$ hybrid rats were examined for loss of heterozygosity $(\mathrm{LOH})$ at each chromosomal region containing these QTL. This report reviews our extensive genetic analysis of rat 4NQO-induced TCs and discusses possible candidate genes with special reference to genetic alterations in TCs and the metabolic activation of the carcinogen [6-10].

\section{Materials and Methods}

\section{Animals}

Inbred DA rats were established at Columbia University (New York, N.Y., USA) from a progenitor related to Copenhagen rats, and were introduced to Kumamoto University (Kumamoto, Japan) in 1973 from the Australian National University (Canberra, Australia). At present, they are commercially available from the Shizuoka Laboratory Animal Centre (SLC, Hamamatsu, Japan). The DA rats used in this study were purchased from SLC. WF rats were originally obtained from Hiroshima University (Hiroshima, Japan) and have been maintained by brother-sister mating for over 90 generations at Kagoshima University (Kagoshima, Japan).

For genetic analysis, reciprocal $\mathrm{F}_{1}$ and $\mathrm{F}_{2}$ intercrosses between DA and WF rats were prepared. All rats were individually numbered and housed in plastic cages in a room air-conditioned to 22 $\pm 2{ }^{\circ} \mathrm{C}$ and fed commercial rat pellets CE-2 (Nippon Clea Co., Tokyo, Japan). No spontaneous tumours were observed at 6 months of age in rats of either parental strain.

\section{Induction of Tongue Cancers}

Starting at 6 weeks of age, rats in the experimental group were given drinking water containing $0.001 \%$ 4NQO ad libitum from 5 p.m. to 9 a.m., but no water was given at other times. They were sacrificed when they became moribund or on the 180th experimental day if still alive. A full autopsy with histopathological examination was carried out. The number of TCs with diameters $>3 \mathrm{~mm}$ (TC\#3), and the diameter of the largest TC were selected as parameters for QTL analysis.

\section{Linkage Analysis}

Linkage analysis was done by interval mapping with a PCRbased method of microsatellite analysis [11]. Of 873 microsatellite loci examined, 267 (30.5\%) were polymorphic between DA and WF. The approximate coverage was $\sim 92 \%$ of the entire rat genome when a marker locus was assumed to detect linkage within a 15-cM chromosomal segment. QTL analysis and lod score calculations were carried out using a Mapmaker/QTL computer package as described previously [8]. For RNO1, composite interval mapping was used to confirm the presence of two independent peaks of linkage with Cartographer QTL software, version 1.13 [12].
According to the criteria of Lander and Kruglyak [13], linkages in the $F_{2}$ intercross were taken as significant when the $p$ value was $<1 \times 10^{-4}$ (lod score $>4.3$ ), and as suggestive if $1 \times 10^{-4}<\mathrm{p}<3.4$ $\times 10^{-3}$ (lod score $<4.3$ and $>2.8$ ). Correlations between the number of TCs and tumour diameter were evaluated by correlation analysis with StatView, version 4.02, software (Abacus Concepts, Inc., Berkeley, Calif., USA). The relative map positions of microsatellite loci were based on the findings of Jacob et al. [14] and Watanabe et al. [15]

\section{LOH Analysis}

Of $88(\mathrm{DA} \times \mathrm{WF}) \mathrm{F}_{1}$ rats given $4 \mathrm{NQO}$ as described above, 40 developed at least one TC with a diameter $>3 \mathrm{~mm}$. Paired samples of the largest TC and the kidney or tail from each of a total of 51 tumour-bearing $\mathrm{F}_{1}$ rats were obtained and stored at $-80^{\circ} \mathrm{C}$. Tumour tissues were carefully enucleated to avoid normal tissue contamination under a dissecting microscope. LOH was detected using PCRbased microsatellite analysis with fluorescence-tagged primers (Research Genetics, Inc., Huntsville, Ala., USA). One microlitre of PCR product was added to $10 \mu \mathrm{l}$ formamide and $0.5 \mu \mathrm{l}$ of TAMRA 500 size standard (Applied Biosystems, Foster, Calif., USA), and the mixture was applied on a $4 \%$ polyacrylamide $6 \mathrm{M}$ urea gel. PCR conditions for each marker locus were as determined in a preliminary study [10]. The gel was scanned using an ABI Prism $310 \mathrm{Ge}-$ netic Analyser (Applied Biosystems), and data were collected automatically and analysed using GeneScan software (Applied Biosystems). Finally, a Genotyper (Applied Biosystems) was used for allele scoring and assessment of $\mathrm{LOH}$. In constitutional heterozygotes, two alleles are detected in normal tissue; if one is absent in a tumour, the result is LOH. When tumours showed allelic imbalance rather than the complete loss of one allele, the ratio of the tumour signal to that of the normal signal (T1/T2 over N1/N2) was calculated. Ratios of $<0.67$ or $>1.35$ were considered indicative of $\mathrm{LOH}$ for that locus.

\section{Results}

\section{Genetic Susceptibility of DA Rats to 4NQO-Induced $T C$}

$4 \mathrm{NQO}$ is a potent pleiotropic carcinogen for various organs in many animal species. Oral administration to rats of 4NQO dissolved in drinking water induced massforming squamous cell carcinomas of the tongue (fig. 1) and the oral cavity. Among inbred rat strains of DA, Long-Evans/stm, Sprague-Dawley, ACI/Ms, Fischer 344, Donryu, and WF, there were remarkable differences in susceptibility to 4NQO-induced TCs (table 1). DA rats developed the highest number of TCs with larger sizes in shorter latent periods, whereas WF rats developed fewer and smaller TCs than any other strains. Other strains showed susceptibility intermediate between these two strains. From this observation, we concluded that the set of DA and WF rats would be an excellent model to study genetic factors in tongue carcinogenesis. 
Table 1. Difference in susceptibility of 4NQO-induced TC among rat strains ${ }^{\mathrm{a}}$

\begin{tabular}{lllll}
\hline Strain & Rats & $\begin{array}{l}\text { Rats with TC\#5 } \\
\text { (incidence, \%) }\end{array}$ & $\begin{array}{l}\text { DTC } \\
\text { (average } \pm \text { SD) }\end{array}$ & $\begin{array}{l}\text { Survival time, days } \\
\text { (average } \pm \text { SD) }\end{array}$ \\
\hline Dark-Agouti & 47 & $44(94 \%)$ & $12.77 \pm 4.49$ & $171.1 \pm 29.6$ \\
Long-Evance/Stm & 42 & $25(60 \%)$ & $8.08 \pm 3.67$ & $182.0 \pm 38.8$ \\
Sprague-Dawley & 48 & $33(69 \%)$ & $9.03 \pm 4.32$ & $186.2 \pm 31.2$ \\
ACI/Ms & 41 & $33(81 \%)$ & $10.07 \pm 5.39$ & $189.4 \pm 22.5$ \\
Fischer 344 & 48 & $40(83 \%)$ & $10.92 \pm 3.83$ & $199.5 \pm 30.1$ \\
Donryu & 46 & $35(76 \%)$ & $9.67 \pm 2.54$ & $205.4 \pm 31.0$ \\
Wistar/Furth & 50 & $2(4 \%)$ & $1.18 \pm 1.64$ & $238.2 \pm 23.6$ \\
\hline
\end{tabular}

TC\#5 = Number of TCs $\geq 5 \mathrm{~mm}$ in diameter; $\mathrm{DTC}_{\max }=$ diameter of the largest $\mathrm{TC}$ in millimetres.

${ }^{a}$ Cited from Kitano et al. [7] with copyright permission of the publisher.

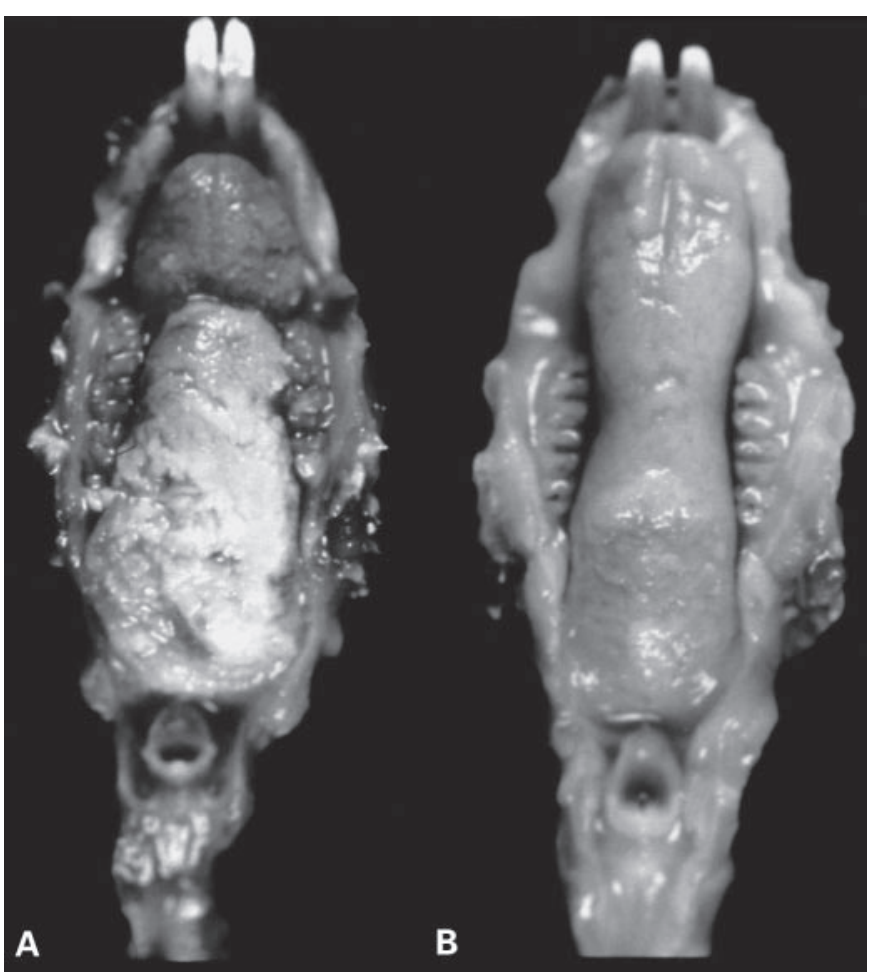

Fig. 1. $4 \mathrm{NQO}$-induced tongue carcinomas in an $\mathrm{F}_{2}$ rat. A Large mass forming cancer. B No macroscopic tumour in this individual.

\section{QTL Determining Host Susceptibility to TCs}

A preliminary whole-genome scanning of 130 extremephenotype $\mathrm{F}_{2}$ rats with 267 markers showed five significant linkages for susceptibility to 4NQO-induced TCs (table 2). The highest linkage peak by the number and size of TC was found on rat chromosome (RNO) 19, at $4 \mathrm{cM}$ distal from D19Mit9. The $\mathrm{p}$ values at the peak were 4.82 $\times 10^{-10}$ for number and $1.48 \times 10^{-9}$ for size of TCs (lod scores, 10.04 and 8.25, respectively, fig. 2). We named this QTL Tongue squamous cell carcinoma-1 (Tscc1). The function of Tsccl was semi-dominant because the number and size of TCs in heterozygous $F_{2}$ rats were intermediate between the high values in the DA-allele homozygotes and the low ones in the WF-allele homozygotes. Tsccl explains the $20.9 \%$ variance of phenotype for number and $17.9 \%$ for size.

A significant QTL peak was observed in the distal region of RNO1, $4 \mathrm{cM}$ distal from D1Rat320, in both number and size (fig. 3). At this peak, the $\mathrm{p}$ values for TC number and size were $5.02 \times 10^{-8}$ and $4.76 \times 10^{-8}(\mathrm{lod}$ score, 6.85 and 6.79$)$, respectively. This locus was named Tsce2.

On RNO1, besides Tscc2, there was a second peak of QTL (Tscc3) for the number of TC at $2 \mathrm{cM}$ distal from D1Mit5. To confirm that the two QTL are independent rather than a random fluctuation of phenotypes, composite interval mapping was carried out with the Cartographer software. It was concluded that this $T s c c 3$ locus was independent from $T s c c 2$. At $T s c c 3$, the $\mathrm{p}$ value for the number of TCs was $2.48 \times 10^{-7}$ (lod score, 4.93). The semi-dominant phenotypic effect of $T s c c 3$ was considerably weaker than that of $T s c c 2$, and its effect on TC size was not significant.

On RNO4, we mapped another locus (Tscc4) linked to the number of TCs. Again, the DA alleles were associated with higher TC phenotype values. At $4 \mathrm{cM}$ distal from $D 4 M g h 10$, the $\mathrm{p}$ value for the number of TCs was $3.34 \times 10^{-8}$ (lod score, 6.88) (fig. 4). The phenotypic effect of Tsce 4 on the size of TCs was below a significance level (lod score, 3.13). 
Table 2. QTL affecting susceptibility to 4NQO-induced TC
Fig. 2. Rat chromosome 19 (RNO19) bearing Tsccl and syntenic chromosomal regions of mouse (MMU) and human (HSA). Bar represents the $T s c c 1$ region of lod score $>4.3$.

\begin{tabular}{|c|c|c|c|c|c|c|c|}
\hline \multirow[t]{3}{*}{ Locus } & \multirow[t]{3}{*}{ RNO } & \multicolumn{6}{|c|}{ Linkage indexes and \% variance explained at each locus } \\
\hline & & \multicolumn{3}{|l|}{ TCs } & \multicolumn{3}{|c|}{ size of the largest TC } \\
\hline & & $\mathrm{p}$ & lod score & $\%$ a & $\mathrm{p}$ & lod score & $\%{ }^{\mathrm{a}}$ \\
\hline Tscel & 19 & $4.82 \times 10^{-10}$ & 10.04 & 20.9 & $1.48 \times 10^{-9}$ & 8.25 & 17.9 \\
\hline$T s c c 2$ & 1 & $5.07 \times 10^{-8}$ & 6.85 & 13.8 & $4.76 \times 10^{-8}$ & 6.79 & 12.9 \\
\hline Tscc3 & 1 & $2.48 \times 10^{-7}$ & 4.93 & 10.7 & $5.26 \times 10^{-6}$ & 3.66 & 9.21 \\
\hline Tsce 4 & 14 & $3.34 \times 10^{-8}$ & 6.88 & 14.4 & $8.72 \times 10^{-4}$ & 3.13 & 7.01 \\
\hline Tscc 5 & 14 & $7.48 \times 10^{-9}$ & 7.29 & 15.3 & $1.92 \times 10^{-3}$ & 3.10 & 6.81 \\
\hline$D 5 M g h 4^{\mathrm{b}}$ & 5 & $1.36 \times 10^{-4}$ & 3.47 & 7.92 & $3.25 \times 10^{-3}$ & 2.83 & 5.92 \\
\hline D6Rat5 $5^{\mathrm{b}}$ & 6 & $2.23 \times 10^{-4}$ & 3.29 & 7.32 & $5.44 \times 10^{-4}$ & 2.75 & 5.78 \\
\hline D10Mit $5^{\mathrm{b}}$ & 10 & $1.45 \times 10^{-3}$ & 3.12 & 6.91 & $9.47 \times 10^{-3}$ & 2.13 & 5.49 \\
\hline
\end{tabular}

a \% variance of phenotype explained.

${ }^{b}$ The marker locus closest to the suggested QTL peak.
On RNO14, we mapped a fifth QTL (Tscc5) linked to the number of TCs. The DA allele is associated with an increased phenotype value. At $2 \mathrm{cM}$ distal from D14Wox4, the $\mathrm{p}$ value for TC\#3 was $7.48 \times 10^{-9}$ (lod score, 7.29) (fig. 5). Tscc5 mainly affected the number of TCs in a semi-dominant trait, while the linkage for TC size of was just suggestive (lod score, 3.10).

In addition to the 5 QTL noted above, a suggestive linkage for phenotypic values either by number or size was observed at four loci: D5Mgh4 on RNO5, D6Rat45 on RNO6, D10Mit8 on RNO10, and D17Wox22 on RNO17. Tentatively, they were identified as suggestive QTL. Among them, special attention should be given to the QTL on RNO5, as frequent loss of the WF chromosomal segment of RNO5 was found where this QTL and the tumour suppressor genes $p 15$ and $p 16$ were mapped. In larger TCs, point mutations and methylation of $p 15$ and $p 16$ also occurred [16]. Polymorphism in the germline as well as somatic changes may contribute to the progression of TCs. Unlike human TCs [16], genetic changes 
Fig. 3. RNO1 bearing $T s c c 2$ and $T s c c 3$ and syntenic chromosomal regions of mouse (MMU) and human (HSA). Bars represent $T s c c 2$ and $T s c c 3$ regions of lod score $>4.3$.

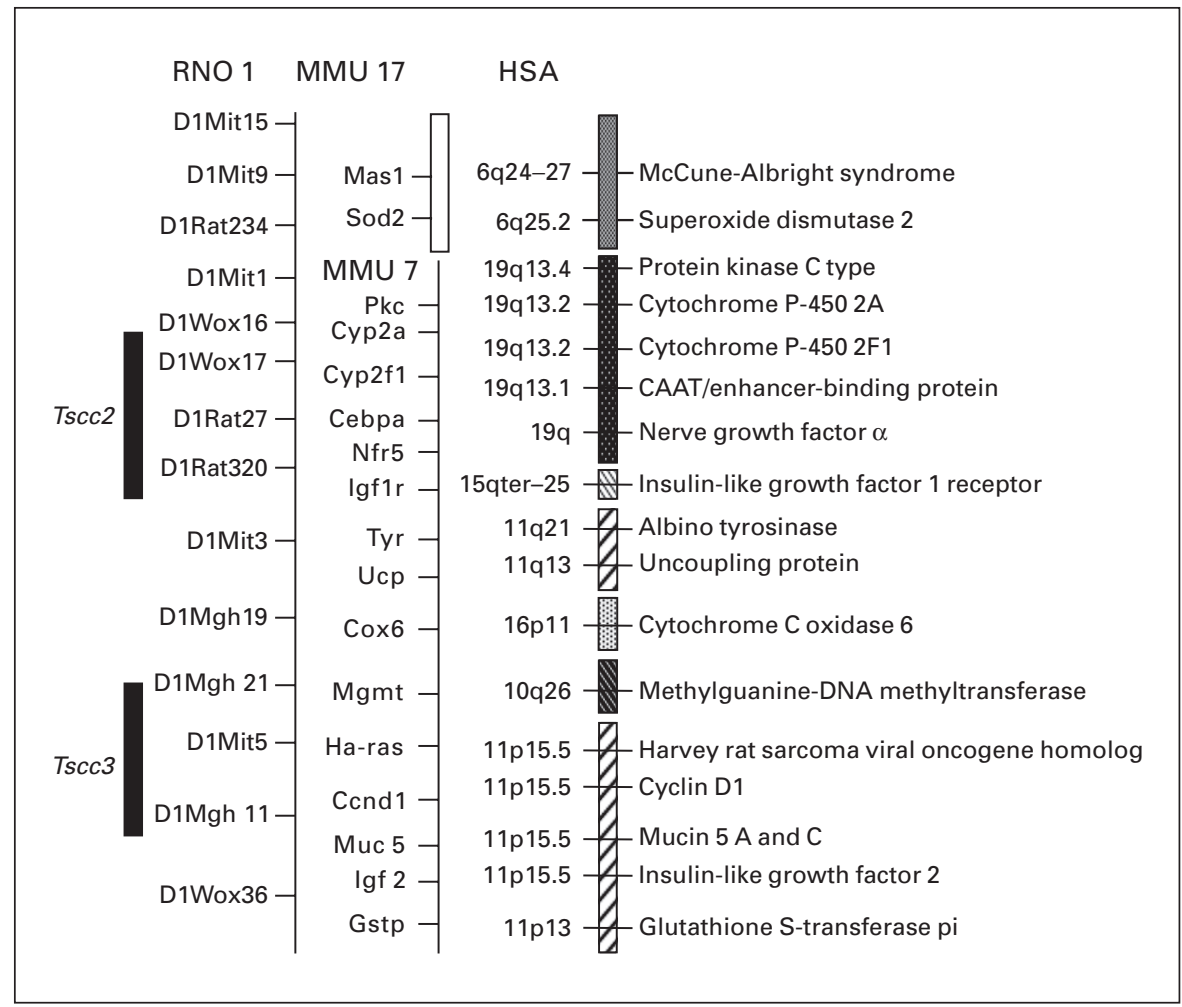

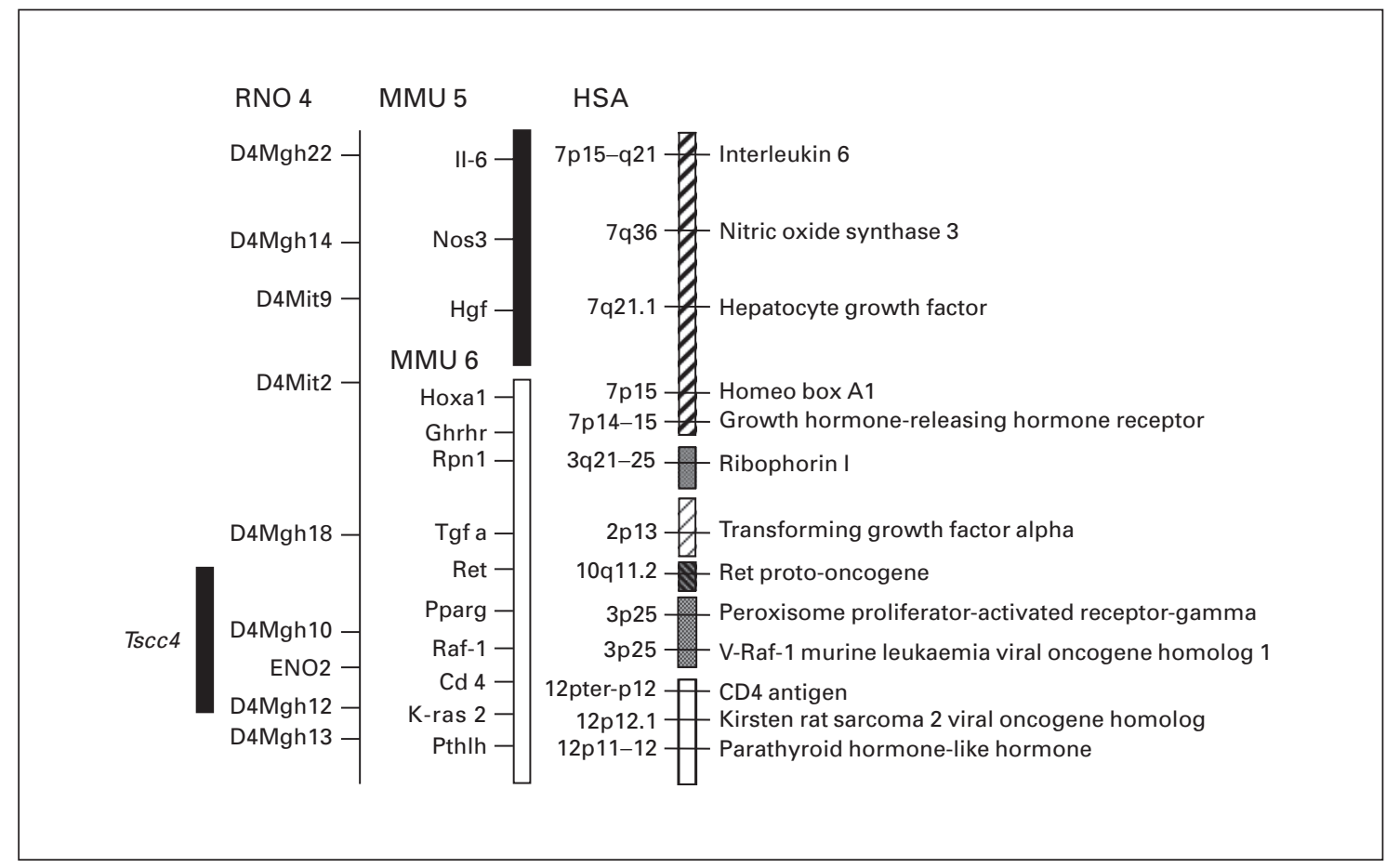

Fig. 4. RNO4 bearing Tscc4 and syntenic chromosomal regions of mouse (MMU) and human (HSA). Bar represents $T s c c 4$ regions of lod score $>4.3$. 
Fig. 5. RNO14 bearing $T s c c 5$ and syntenic chromosomal regions of mouse (MMU) and human (HSA). Bar represents Tscc5 regions of lod score $>4.3$.

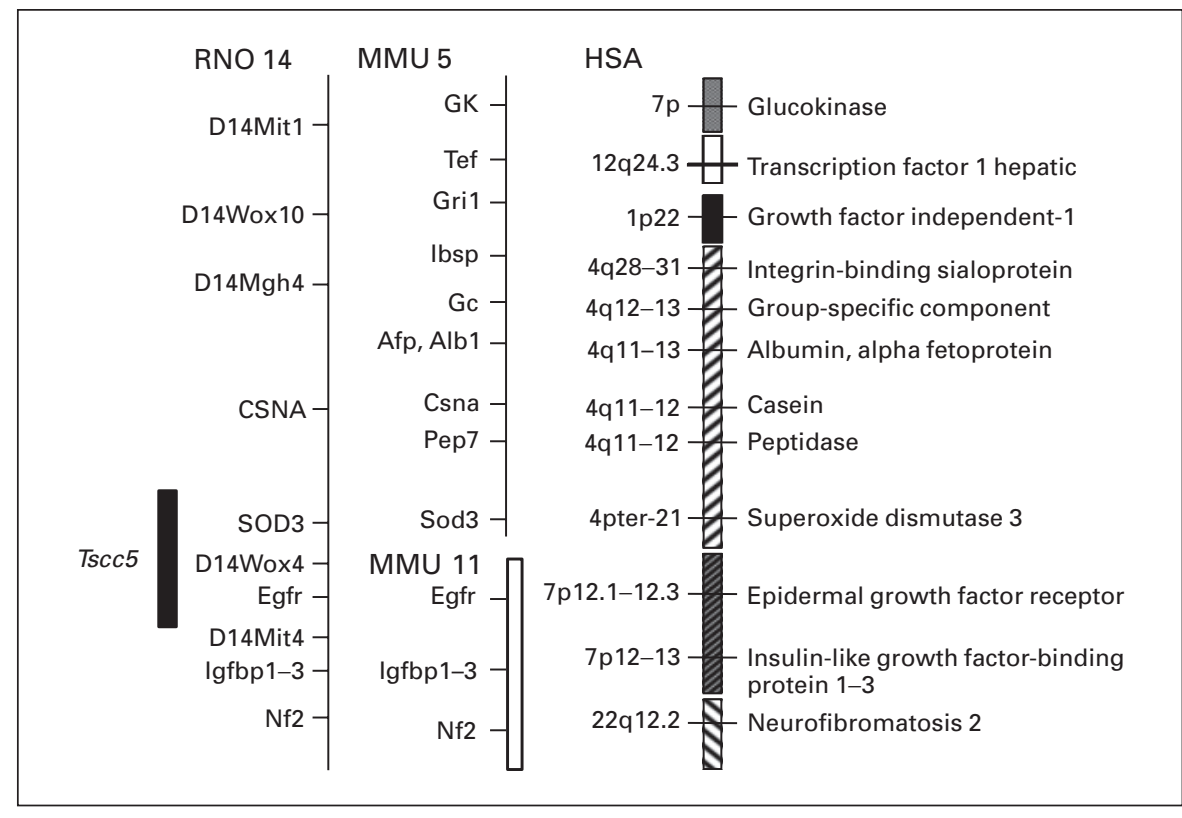

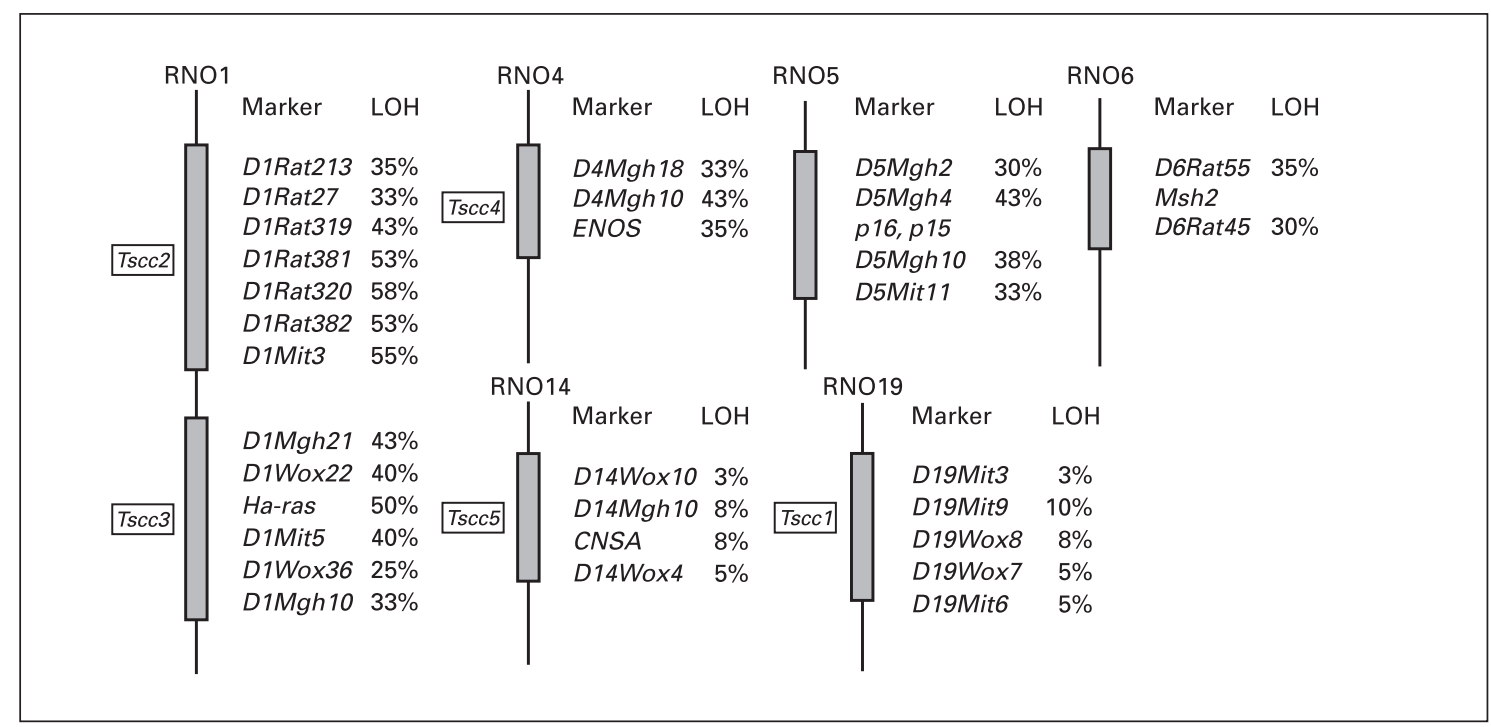

Fig. 6. Distribution of QTL affecting the size of TCs and percent frequency of LOH at each QTL.

in $p 53$ were not frequent in the 4NQO-induced rat TCs except in some large TCs.

\section{Survey of LOH in TCs Induced in $F_{1}$ Rat}

To determine whether the resistant WF alleles of these loci are lost by hemizygous deletion, as seen in tumour suppresser genes, we first examined LOH in the TCs of the 40 reciprocal $(\mathrm{DA} \times \mathrm{WF}) \mathrm{F}_{1}$ rats with tumours $\geq 5 \mathrm{~mm}$ in diameter. $\mathrm{LOH}$ was frequently found on RNO1, 4, 5, and 6 and less frequently on RNO10, 14, and 19 (fig. 6). Among Tscc loci, Tscc2, Tscc3 (on RNO1) and Tscc4 (on RNO4) were within the segments frequently involved in LOH. In contrast, Tsccl (RNO19) and Tscc5 (RNO14) were not involved in LOH. In Tscc2, Tscc3, and 


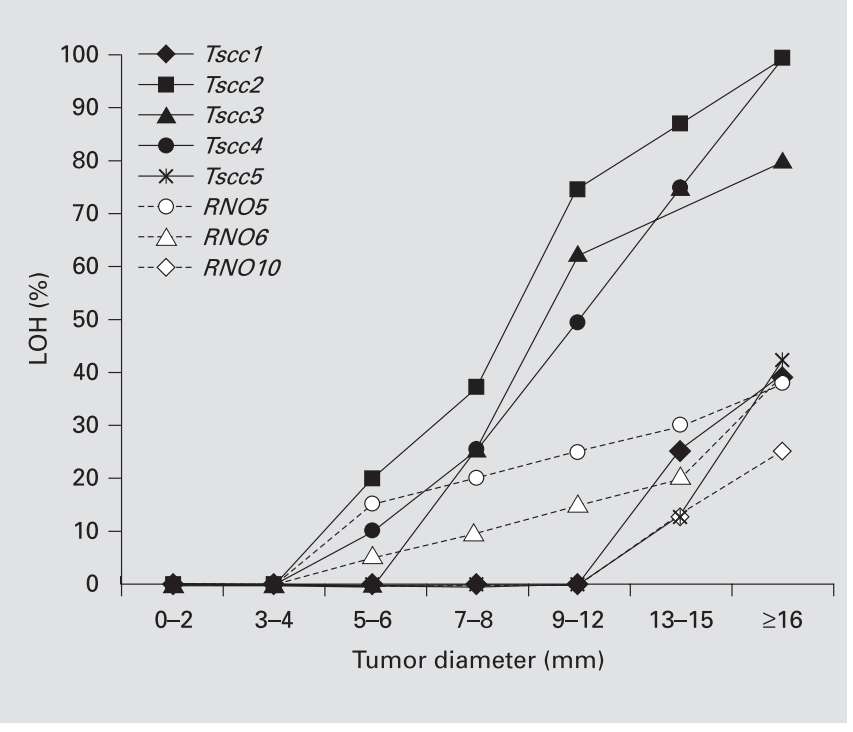

Fig. 7. $\mathrm{LOH}$ at each $T$ scc locus and size of TCs.

Tscc4, the WF allele was preferentially lost and LOH frequency increased in parallel with the size of the TC, raising the possibility that the functions of these QTL are to suppress tumour progression [16]. Other hot spots showing $>30 \%$ frequency were on RNO5 and 6 , bearing $p 15_{I N K 4 B} / p 16_{I N K 4 A}$ and $M s h 2$, respectively. We also examined TCs in reciprocal $F_{1}$ rats; however, no imprinting was observed at any of these loci.

\section{Discussion}

The plethora of host genetic control of 4NQO-induced tongue cancers in rats is not exceptional for the model introduced here. Similar complexity has been observed in chemically induced lung adenomas [17-19], liver cancers $[20,21]$, and skin cancers $[22,23]$. The molecular bases of QTL found in this study have not been elucidated, but candidate genes for them include genes encoding enzymes metabolising the carcinogen, growth factors, and their receptor, oncogene, and onco-suppresser genes. It is also possible that some of them are responsible for immune responses to developing TCs. At present, it would be premature to assign them to each QTL, but the following discussion serves as a basis for further investigation.

One of important candidate genes for Tscc 1 was NQO1 (Dia4), the gene encoding quinone oxidoreductase (DT- diaphorase or NADH-cytochrome $b_{5}$ reductase) $[24,25]$. A precisely mapped location of $N Q O 1$ in the rat has not been reported, but it is in the syntenic regions of the human chromosome 16q22.1 and the mouse chromosome 8 [26-28]. Quinone oxidoreductase is one of the major enzymes that convert $4 \mathrm{NQO}$ to the more active metabolite, 4-hydroxyaminoquinoline 1-oxide [25, 27]. Recently, we clarified that the locus of NQO1 is co-mapped with Tsccl between D19Mit9 and D19wox8 [29]. The polymorphism of $N Q O 1$ may well modulate the enzyme activity to activate $4 \mathrm{NQO}$ and, thus, modify the susceptibility to TCs. Actually DA rats show a very high level of $N Q O 1$ mRNA as well as enzymal activity of quinone oxidoreductase [30].

An important candidate for $T s c c 2$ is $C y p 2 a$, located at $19 \mathrm{q} 13.2$, a structural gene for one of the cytochrome P450 enzymes. The P-450 enzymes constitute a superfamily of membrane-bound enzymes that function as terminal mono-oxygenase in the metabolism of a broad variety of endogenous and exogenous compounds, including chemical carcinogens [31, 32]. Another candidate gene for $T s c c 2$ may be $p 57$ of the p57Kip2 protein [33], which is one of the cyclin-dependent kinase $(\mathrm{Cdk})$ inhibitors [34]. When searching for $\mathrm{LOH}$ at Tsce loci in 4NQO-induced $\mathrm{TC}$ in $(\mathrm{DA} \times \mathrm{WF}) \mathrm{F}_{1}$ rats, we found that the chromosomal region of the $T s c c 2$ was a frequent target of $\mathrm{LOH}$; the frequency of which increased as the size of the TCs increased. The resistant WF allele was selectively lost, which suggests that $T s c c 2$ might encode a tumour suppressor gene.

We can assume several candidate genes for $T s c c 3$ from its map position, including Ha-ras [35, 36], CyclinD1 [37], IGF2 [38], and Gstp [39, 40]. Ha-ras genes have previously been implicated in cancer predisposition in humans, mice, and rats [35]. Loss of the wild-type Ha-ras allele may cause an unopposed mutant activated by $\mathrm{p} 21$ protein that could potentially lead to gene amplification [36]. Ha-ras point mutations at codon 12 or 61 were detected in 28 of the $40 \mathrm{TCs}$, among which $\mathrm{LOH}$ of wildtype Ha-ras was observed in 20 of the TCs $>8 \mathrm{~mm}$ in diameter. The high incidence of Ha-ras mutations raises the possibility that they represent an early event in TC development. In our parallel study with 4NQO-induced TCs in $F_{1}$ rats, frequent loss of the WF allele and point mutations in the remaining DA allele at the Ha-ras gene were observed [16].

An earlier study of ours showed Gstp to be a promising marker for 4NQO-induced tongue carcinogenesis in the rat [39]. All TCs invariably expressed Gstp, whereas tongue tissues from normal control animals were nega- 
tive. This may contribute somehow to the difference in susceptibility to $4 \mathrm{NQO}$ between the DA and WF strains $[39,40]$.

One of the candidate genes for $T s c c 4$ is $T g f \alpha$, located on RNO4 and encoding the transforming growth factor- $\alpha$ $[41,42]$. Another candidate gene is p27Kip 1, a $27-\mathrm{kDa}$ Cdk inhibitor [43]. Moreover, other candidate genes for Tscc4 mapped on RNO4 may be Ki-ras [44, 45], Ret [46], Raf-1 [47], and Pthlh. Pthlh encodes the parathyroid hormone-related protein, which is regarded as a predominant cause of hypercalcaemia of malignancies observed in several types of human cancers [48, 49]. Manenti et al. [50] reported that an amino acid polymorphism of Pthlh showed cancer modifier effects in a human squamous cell carcinoma cell line. We also are now engaged in an exhaustive molecular survey on Pthlh, in respect to 4NQOinduced rat tongue carcinogenesis, and some important and interesting results will hopefully be presentable in the future [Tanuma, unpublished data]. For $T s c c 5, E g f r$ [51] and $T p 5312$ [52] can be mentioned as possible candidate genes.

Carcinogenesis is a multifactorial disease. Numerous genes in the complicated biochemical steps involved in carcinogenesis may be genetically polymorphic. A sum of such a polymorphic effect is the visible difference between strains. Although it is not straightforward to compare the results in rats with those in humans, it is possible that some of the steps in carcinogenesis are shared across species. We believe that the comparative approach is still an effective means of understanding the genetic basis of differences in cancer susceptibility among individuals.

\section{Conclusion}

The results of this study indicate that the 4NQO-induced TC in the rat is a multifactorial disease of a polygenic trait. This model will be useful to understand the complicated genetic basis of predisposition to oral cancers.

\section{Acknowledgements}

This research was supported by a Grant-in-Aid for Cancer Research from the Ministry of Health, Labour and Welfare of Japan (No. 13-2), and a Grant-in-Aid from the Japan Society for the Promotion of Science (No. 16591892).

\section{References}

1 Foulkes WD, Brunet JS, Kowalski LP, Narod SA, Franco EL: Family history of cancer is a risk factor for squamous cell carcinoma of the head and neck in Brazil: a case control study. Int J Cancer 1990;62:847-851.

-2 Franceschi S, Barra S, Vecchia C, Bidoli E, Negri E, Talamini R: Risk factors for cancer of the tongue and mouth: a case-control study from Northern Italy. Cancer 1992; 70:2227-2233.

- 3 Houck JR, Romano PJ, Batholomew M, Smith $P$ : Do histocompatibility antigens influence the risk of head and neck carcinoma? Cancer 1992; 69:2327-2332.

4 Goldstein AM, Blot WJ, Greenberg RS, Schoenberg JB, Austin DF, Preston-Martin S, Winn DM, Bernstein L, McLaughlin JK, Fraumeni JF Jr: Familial risk in oral and pharyngeal cancer. Eur J Cancer B Oral Oncol 1994; 30B:319-322.

-5 Yu GP, Zhang ZF, Hsu TC, Spitz MR, Schantz SP: Family history of cancer, mutagen sensitivity, and increased risk of head and neck cancer. Cancer Lett 1999;146:93-101.

-6 Kitano M, Hatano H, Shisa H: Strain difference of susceptibility to 4-nitroquinoline 1-oxide-induced tongue carcinoma in rats. Jpn $\mathrm{J}$ Cancer Res 1992;83:843-850.
Kitano M, Hirayama Y, Tanuma J, Matsuuchi H, Li T-J, Semba I, Kokubu T, Hatano H, Tada M, Kobayashi Y, Shisa H: Genetic controls of susceptibility and resistance to 4-nitroquinoline 1-oxide-induced tongue carcinomas in rats. Jpn J Cancer Res 1996;87:1097-1101.

${ }_{8}$ Tanuma J, Shisa H, Hiai H, Higashi S, Yamada H, Kamoto T, Hirayama Y, Matsuuchi H, Kitano M: Quantitative trait loci affecting 4nitroquinoline 1-oxide-induced tongue carcinogenesis in the rat. Cancer Res 1998;58: $1660-1664$.

-9 Tanuma J, Kitano M, Shisa H, Hiai H: Polygenetic susceptibility and resistance to 4-nitroquinoline 1-oxide-induced tongue carcinomas in the rat. J Exp Anim Sci 2000;41:68-77. 10 Tanuma J, Fujii K, Hirano H, Matsuuchi H,
Shisa H, Hiai H, Kitano M: Five quantitative trait loci affecting 4-nitroquinoline 1-oxide-induced tongue cancer in the rat. Jpn J Cancer Res 2001;92:610-616.

11 Yamada Y, Matsushiro H, Ogawa MS, Okamoto K, Nakakuki Y, Toyokuni S, Fukumoto M, Hiai H: Genetic predisposition to pre-B lymphomas in SL/Kh strain mice. Cancer Res 1994;54:403-407.
12 Basten CJ, Weir BS, Zeng ZB: QTL Cartographer Version: A Reference Manual and Tutorial for QTL Mapping. Program in Statistical Genetics. Raleigh, Department of Statistics, North Carolina University, 1999, pp 1-132.

13 Lander ES, Kruglyak L: Genetic dissection of complex traits: guidelines for interpreting and reporting linkage results. Nat Genet 1995;11: 241-247.

14 Jacob H, Brown DM, Bunker RK, Daly MJ, Dzau VJ, Goodman A, Koike G, Kern V, Kurtz T, Lernmark A, Levan G, Mao Y, Petterson A, Pravenec M, Simon JS, Szpirer C, Szpirer J, Trolliet MR, Winer ES, Lander ES: A genetic linkage map of the laboratory rat, Rattus norvegicus. Nat Genet 1995;9:63-69.

15 Watanabe TK, Bihoreau MT, McCarthy LC, Kiguwa SL, Hishigaki H, Tsuji A, Browne J, Yamasaki Y, Mizoguchi-Miyakita A, Oga K, Ono T, Okuno S, Kanemoto N, Takahashi E, Tomita K, Hayashi H, Adachi M, Webber C, Davis M, Kiel S, Knights C, Smith A, Critcher R, Miller J, Thangarajah T, Day PJ, Hudson JR Jr, Irie Y, Takagi T, Nakamura Y, Goodfellow PN, Lathrop GM, Tanigami A, James MR: A radiation hybrid map of the rat genome containing 5,255 markers. Nat Genet 1999;22: 27-36. 
16 Tanuma J, Hiai H, Shisa H, Hirano M, Semba I, Nagaoka S, Kitano M: Carcinogenesis modifier loci in rat tongue are subject to frequent loss of heterozygosity. Int J Cancer 2002;102: 638-642.

17 Malkinson AM, Nesbitt MN, Skamene E: Susceptibility to urethan-induced pulmonary adenomas between $\mathrm{A} / \mathrm{J}$ and $\mathrm{C} 57 \mathrm{BL} / 6 \mathrm{~J}$ mice: use of AXB and BXA recombinant inbred lines indicating a three-locus genetic model. J Natl Cancer Inst 1985;75:971-974.

$\checkmark 18$ Lee GH, Matsushita H, Kitagawa T: Fine chromosomal localization of the mouse Par2 gene that confers resistance against urethane-induction of pulmonary adenomas. Oncogene 2001; 20:3979-3985.

-19 Manenti G, Galbiati F, Gianni-Barrera R, Pettinicchio A, Acevedo A, Dragani TA: Haplotype sharing suggests that a genomic segment containing six genes accounts for the pulmonary adenoma susceptibility 1 (Pas 1) locus activity in mice. Oncogene 2004;27;23:44954504.

20 De Miglio MR, Pascale RM, Simile MM, Muroni MR, Calvisi DF, Virdis P, Bosinco GM, Frau M, Seddaiu MA, Ladu S, Feo F: Chromosome mapping of multiple loci affecting the genetic predisposition to rat liver carcinogenesis. Cancer Res 2002;62:4459-63.

-21 Yan Y, Zeng ZZ, Higashi S, Denda A, Konishi Y, Onishi S, Ueno H, Higashi K, Hiai H: Resistance of DRH strain rats to chemical carcinogenesis of liver: genetic analysis of later progression stage. Carcinogenesis 2002;23: 189-196.

-22 Nagase H, Mao JH, Balmain A: A subset of skin tumour modifier loci determines survival time of tumour-bearing mice. Proc Natl Acad Sci USA 1999;96:15032-15037.

-23 Gariboldi M, Peissel B, Fabbri A, Saran A, Zaffaroni D, Falvella FS, Spinola M, Tanuma J, Pazzaglia S, Mancuso MT, Maurichi A, Bartoli C, Cataltepe S, Silverman GA, Pilotti S, Hayashizaki Y, Okazaki Y, Dragani TA: SCCA2-like serpins mediate genetic predisposition to skin tumours. Cancer Res 2003;63: 1871-1875.

-24 Cohen BS, Estabrook RW: Microsomal electron transport reactions. 1. Interaction of reduced triphosphopyridine nucleotide during the oxidative demethylation of aminopyrine and cytochrome b5 reduction. Arch Biochem Biophys 1971;143:37-45.

-25 Lind C, Rase B, Ernster L, Townsend M, Martin D: Strain difference in DT-diaphorase activities. FEBS Lett 1973;37:147-148.

-26 Serikawa T, Cui Z, Yokoi N, Kuramoto T, Kondo Y, Kitada K, Guenet JL: A comparative genetic map of rat, mouse and human genomes. Exp Anim 1998;47:1-9.

$>27$ Becker-Follmann J, Gaa A, Bausch E, Natt E, Scherer G, Von Deimling O: High-resolution mapping of a linkage group on mouse chromosome 8 conserved on human chromosome 16Q. Mamm Genome 1997;8:172-177.
8 Chen H, Lum A, Seifried A, Wilkens LR, Marchand LL: Association of NAD(P)H: quinone oxidoreductase 609C-T polymorphism with a decreased lung cancer risk. Cancer Res 1999;59:3045-3048.

29 Hirano M: Polymorphism of NQO1 (C609T) in relation to susceptibility to oral squamous cell carcinoma. Oral Med Pathol 2003;8:3741.

30 Hirano M, Tanuma J, Hirayama Y, Ohyama M, Semba I, Wakusawa S, Shisa H, Hiai H, Kitano M: A speed congenic rat strain bearing the tongue cancer susceptibility locus Tsccl from Dark-Agouti rats. Cancer Lett 2005, in press.

31 Serikawa T, Cui Z, Yokoi N, Kuramoto T, Kondo Y, Kitada K, Guenet JL: A comparative genetic map of rat, mouse and human genomes. Exp Anim 1998;47:1-9.

32 Rampersaud A, Walz FG Jr: Mapping of genes for cytochromes P-450b, P450e, P-450g, and P-450h in the rat. J Biol Chem 1987;262:5649_ 5663.

33 Balasubramanian S, Ahmad N, Jeedigunta S, Mukhtar H: Alterations in cell cycle regulation in mouse skin tumours. Biochem Biophys Res Commun 1998;243:744-748.

34 Watanabe H, Pan ZQ, Schreiber AN, DePinho RA, Hurwitz J, Xiong Y: Suppression of cell transformation by the cyclin-dependent kinase inhibitor p57KIP2 requires binding to proliferating cell nuclear antigen. Proc Natl Acad Sci USA 1998;95:1392-1397.

-35 Suzui M, Yoshimi N, Tanka T, Mori H: Infrequent Ha-ras mutation and absence of Ki-ras, $\mathrm{N}$-ras, and p53 mutations in 4-nitroquinoline 1-oxide-induced rat oral lesions. Mol Carcinog 1995; 14:294-298.

36 Gollahon LS, Chen A, Aldaz CM: Loss of heterozygosity at chromosome 1q loci in rat mammary tumours. Mol Carcinog 1995;12:7-13.

37 Lee CCR, Yamamoto S, Wanibuchi H, Wada S, Sugimura K, Kishimoto T, Fukushima S: Cyclin D1 overexpression in rat two-stage bladder carcinogenesis and its relationship with oncogenes, tumour suppressor genes, and cell proliferation. Cancer Res 1997;57:47654776 .

38 Sciacca L, Costantino A, Pandini G, Mineo R Frasca F, Scalia P, Sbraccia PD, Goldfine I, Vigneri R, Belfiore A: Insulin receptor activation by IGF-II in breast cancers: evidence for a new autocrine/paracrine mechanism. Oncogene 1999; 18:2471-2479.

39 Li TJ, Hirayama Y, Kitano M: Glutathione Stransferase $\pi$ class as a tumour marker in lingual preneoplastic and neoplastic lesions of rats. Virchows Arch 1997;431:37-43.
40 Matsuda R, Yoshida MC, Sakaki M, Okuda A, Sakai M, Muramatsu M: Location of the gene for glutathione S-transferase $\pi$ on rat chromosome 1 at band q43. Jpn J Cancer Res 1986; 77:1055-1058

41 Donnelly MJ, Patel V, Yeudall WA, Game SM, Scully C, Prime SS: Autocrine production of TGF- $\alpha$ and TGF- $\beta$ during tumour progression of rat oral keratinocytes. Carcinogenesis 1993; 14:981-985.

42 Wong DT: TGF-alpha and oral carcinogenesis. Eur J Cancer B Oral Oncol 1993;29B:3-7.

43 Nomura H, Sawada Y, Fujinaga K, Ohtaki S: Cloning and characterization of rat p27Kip1, a cyclin-dependent kinase inhibitor. Gene 1997; 192:211-218.

44 Hegi ME, Devereux TR, Dietrich WF, Cochran CJ, Lander ES, Foley JF, Maronpot RR, Anderson MW, Wiseman RW: Allelotype analysis of mouse lung carcinomas reveals frequent allelic losses on chromosome 4 and an association between allelic imbalances on chromosome 6 and $K$-ras activation. Cancer Res 1994;54:6257-6264.

45 Zhang Z, Wag Y, Vikis HG, Johnson L, Liu G, Li J, Anderson MW, Sills RC, Hong HL, Devereux TR, Jacks T, Guan KL, You M: Wildtype Kras 2 inhibit lung carcinogenesis in mice. Nat Genet 2001;29:25-33.

46 Takahashi M, Ritz J, Cooper GM: Activation of a novel human transforming gene, ret, by DNA rearrangement. Cell 1985;42:581-588.

47 Lee SW, Fang L, Igarashi M, Ouchi T, Lu KP, Aaronson SA: Sustained activation of Ras/Raf/ mitogen-activated protein kinase cascade by the tumour suppressor p53. Proc Natl Acad Sci USA 2000;97:8302-8305.

48 Heath DA, Senior PV, Varley JM, Beck F: Parathyroid-hormone-related protein in tumours associated with hypercalcaemia. Lancet 1990;335:66-69.

49 Iwamura M, di Sant'Agnese PA, Wu G, Benning CM, Cockett AT, Deftos LJ, Abrahamsson PA: Immunohistochemical localization of parathyroid hormone-related protein in human prostate cancer. Cancer Res 1993;53: 1724-1726.

50 Manenti G, Peissel B, Gariboldi M, Falvella FS, Zaffaroni D, Allaria B, Pazzaglia S, Rebessi S, Covelli V, Saran A, Dragani TA: A cancer modifier role for parathyroid hormone-related protein. Oncogene 2000;19:5324-5328.

51 Ohyama M, Hirayama Y, Tanuma J, Hirano M, Semba I, Shisa H, Hiai H, Sugihara K, Kitano $\mathrm{M}$ : Expression of junB and c-fos are enhanced 4-nitroquinoline 1-oxide-induced rat tongue cancers. Pathol Int 2004;54:35-40.

-52 Neyns B, Katesuwansing, Vermeij J, Bourgain C, Vandamme B, Amfo K, Lissens W, DeSutter P, Hooghe PE, DeGreve J: Expression of jun family of genes in human ovarian and normal ovarian surface epithelium. Oncogene 1996; 12:1247-1257. 